\title{
MEDIA PROMOSI PENANGKARAN RUSA SAMBAR (RUSA UNICOLOR) SEBAGAI EKOWISATA DI PENAJAM PASER UTARA BERBASIS VIRTUAL REALITY
}

\author{
Andi Tejawati', Muhammad Budi Saputra², Muhammad Bambang Firdaus ${ }^{3}$, \\ Sofiansyah fadli ${ }^{4}$, fadli suandi ${ }^{5}$, M. Khairul Anam 6 \\ Universitas Mulawarman, Samarinda 1,2,3 \\ STMIK Lombok, Lombok Tengah 4 \\ Politeknik Negeri Batam, Batam ${ }^{5}$ \\ STMIK Amik Riau, Pekanbaru ${ }^{6}$ \\ Barong Tongkok Kampus Gn.Kelua Universitas Mulawarman 1,2,3 \\ Jl. Rahmat basuki, Praya Lombok Tengah 4 \\ Jl. Ahmad yani, Batam Kota, Kepulauan Riau ${ }^{5}$ \\ Jl. Purwodadi Indah, Km 10 Panam, Pekanbaru ${ }^{6}$ \\ ${ }^{1}$ anditejawati117@yahoo.com, ${ }^{2}$ budisaputra34@gmail.com, ${ }^{3}$ bambangf@fkti.unmul.ac.id,
${ }^{4}$ sofiansyah182@gmail.com , 5 fadli.suandi@polibatam.ac.id , ${ }^{6}$ khairulanam@sar.ac.id
}

\begin{abstract}
The purpose of this research is to create a promotional media about the ecotourism of deer breeding in Desa Api-api, Kecamatan Waru, Penajam Paser Utara. It is hoped to be able to add information to the public and outside tourists about the ecotourism of deer breeding in Api-Api Village, as well as attracting the interest of people and tourists outside the area for a date to the sambar deer breeding in Penajam Paser Utara. To achieve the objectives of this research, the incorporation of Virtual Reality (VR) technology can display virtual objects into real environments and Android mobile technology that is needed by many people. To build Android-based Virtual Reality applications use the Unity3D game engine and use Adobe Premiere Pro video editing tools to install 360 degree videos. The test results on Android devices show that the application is made to run and match based on the active gyroscope on the smartphone and can be used on Android 6.0 and above with a 16: 9 screen aspect ratio.
\end{abstract}

Keyword : Virtual Reality, Ekowisata, Penajam Paser Utara.

\begin{abstract}
Abstrak
Tujuan penelitain ini adalah membuat media promosi untuk mengenai ekowisata penangkaran rusa yang berada di Desa Api-api, Kecamatan Waru, Penajam Paser Utara. Diharapkan bisa menambah informasi kepada masyarakat dan wisatawan luar daerah mengenai ekowisata penangkaran rusa di Desa Api-Api, serta menarik minat masyarakat dan wisatawan luar daerah untuk dating ke penangkaran rusa sambar yang ada di Penajam Paser Utara. Untuk mencapai tujuan dari penelitian tersebut digunakan penggabungan teknologi Virtual Reality (VR) yang dapat menampilkan objek virtual kedalam lingkungan yang nyata dan teknologi mobile Android yang dimiliki oleh banyak masyarakat. Untuk membangun aplikasi Virtual Reality berbasis Android digunakan game engine Unity3D dan menggunakan tools editing video Adobe Premiere Pro untuk mengedit video 360 derajat. Hasil pengujian pada perangkat android menunjukan aplikasi yang dibuat dapat berjalan lancar dan cocok berdasarkan keaktifan gyroscope pada smarphone dan bisa digunakan pada versi Android 6.0 keatas dengan aspek rasio layar 16:9.
\end{abstract}

Kata kunci : Virtual Reality, Ekowisata, Penajam Paser Utara.

ISSN. 2620-6900 (Online) 2620-6897 (Cetak) 


\section{Pendahuluan}

Salah satu objek pariwisata di Penajam Paser Utara ini karena banyaknya pemburuan liar terhadap rusa untuk dijual dagingnya oleh oknum-oknum tidak bertanggung jawab. Selain itu banyaknya eksploitasi hutan besar-besaran yang terjadi di Penajam Paser Utara berdampak pada terancamnya kehidupan fauna serta flora di hutan Penajam, salah satunya yaitu Rusa Sambar khas Kalimantan ini. Untuk melindungi rusa yang berpotensi menjadi fauna langka ini maka dibuatlah Taman Wisata Penangkaran Rusa di Desa Api-api, Kecamatan Waru, Penajam Paser Utara.

Kabupaten Penajam Paser Utara merupakan Kabupaten ke 13 di Propinsi Kalimantan Timur yang merupakan pemekaran dari kabupaten Paser pada tahun 2002 terbentuk pada tanggal 11 Maret 2002 berdasarkan UU RI No. 7 Tahun 2002, saat ini terus menjalankan program pengembangan dan pembangunan disegala bidang. Mulai dari peningkatan sarana dan prasarana infrastruktur, peningkatan kualitas Sumber daya manusia, pengembangan pertanian dalam arti luas, pembenahan manajemen pemerintahan.

Salah satu sektor yang saat ini sedang dibenahi adalah sektor Kepariwisataan. Potensi pariwisata di Kabupaten Penajam Paser Utara yang terdiri dari 4 Kecamatan dan 47 desa/kelurahan ini terdiri dari berbagai macam Etnis Suku dan Ras, dengan luas Kabuapeten 3.333.06 kilometer persegi dengan jumlah penduduk 131.878 jiwa. Sebagai daerah otonom baru hasil pemekaran, Kabupaten Penajam Paser Utara berupaya melibatkan semua pihak, khususnya kalangan dunia usaha agar secara bersama-sama Pemerintah Daerah dan Masyarakat mengembangkan sumber daya alam yang ada khusunya sektor Pariwisata.

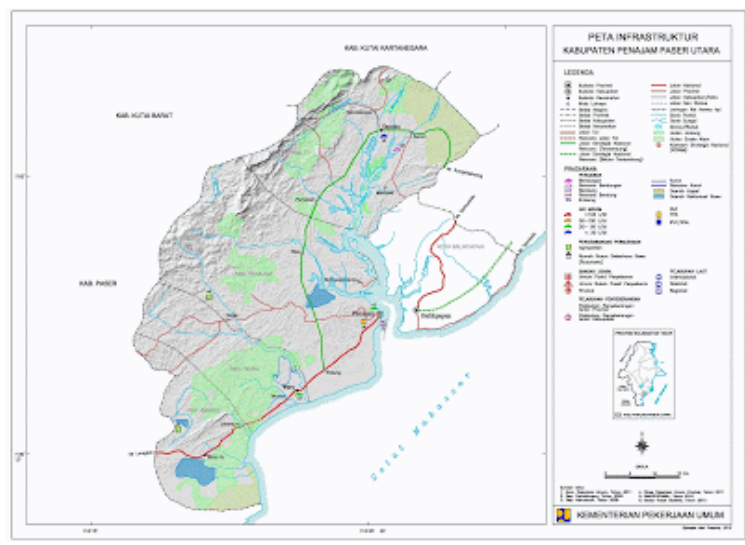

Gambar 1. Peta Penajam Paser Utara
Potensi Pariwisata di Kabupaten Penajam Paser Utara sangat didukung dengan posisi strategisnya sebagai pintu gerbang jalur trans Kalimantan serta menjadi lalu lintas perdagangan antar propinsi. Letaknya berhadapan dengan kota Balikpapan, membuat akses ke Penajam Paser Utara sangat mudah. Jalan raya yang melintas di Kabupaten Penajam Paser Utara merupakan jalan propinsi atau Jalan Negara yang menghubungkan Kalimantan Timur, Kalimantan Tengah dan Kalimantan Selatan

Sebagai objek ekowisata, penangkaran rusa ini membutuhkan sebuah media informasi sebagai sarana untuk meningkatkan daya tarik masyarakat yang akan berkunjung ke penangkaran rusa [1]. Salah satu media informasi selain poster yang digunakan untuk penyebaran informasi tersebut adalah melalui media sosial karena dapat diakses dimana saja oleh pengguna smartphone [2]. Teknologi saat ini yang dapat dimanfaatkan dalam perkembangan media informasi adalah menggunakan Virtual Reality yang di share dalam media social [3].

Virtual Reality adalah video dengan sudut pandang 360 derajat. Virtual Reality ini membuat pengguna seakan-seakan berada langsung dalam lingkungan tersebut [4], [5]. Melalui media ini, diharapkan masyarakat mendapatkan informasi secara visual mengenai penangkaran rusa yang ada di penajam paser utara sehingga masyarakat tertarik untuk mengunjungi penangkaran rusa di Penajam Paser Utara.

\section{Landasan Teori}

\subsection{UPTD. Pembibitan Ternak dan Hijauan Pakan Ternak}

Sejarah tujuan berdirinya UPTD. Pembibitan Ternak dan Hijauan Pakan Ternak Api-Api adalah pada awalnya tahun 1990 berupa Penangkaran Rusa melalui Proyek APBD 1 Dinas Peternakan Provinsi Kalimantan Timur, kegiatan pada saat itu meliputi pemeliharaan Rusa. Dengan berdirìnya UPTD. Pembibitan Ternak dan Hijauan Pakan Ternak Api-Api sebagai pelaksana teknis Dinas Peternakan Provinsi Kalimantan Timur dilanjutkan kegiatan meliputi Pemeliharaan Ternak Rusa, Pemeliharaan Sapi Bali Bibit, Produksi Semen Beku, Penanaman HPT, Perneliharaan Kambing dan Ayam Kampung (Buras), diharapkan mampu menjaga dan mengembangkan plasma nutfah spesifik Kalimantan Timur.

Dalam memenuhi kebutuhan pengembangan bibit ternak diperlukan pusat pengembangan Tekhnologi Petemakan di Provinsi Kalimantan Timur yang mampu memproduksi Bibit Semen 
Beku, Bibit HPT, Bibit Sapi, Bibit Rusa, serta pengolahan pupuk bokasi, pupuk cair dan produk ikutan rusa berupa kapsul ranggah mudah (Velvet) yang memiliki nilai ekonomis. UPTD. Pembibitan Ternak dan Hijauan Pakan Ternak Api-Api Dinas Peternakan dan Kesehatan Hewan Provinsi Kalimantan Timur, sesuai peran dan fungsinya terus berusaha membenahi dan meningkatkan kinerja agar tetap mampu bersaing dan berkontribusi positif terhadap kemajuan dunia peternakan pada umumnya, guna ikut sertaa mendorong dan mensukseskan program Pemerintah di bidang Peternakan yaitu Pencapaian Swasembada Daging dan Ketahanan Pangan Nasional.

\subsection{Ekowisata}

Wisata alam adalah bentuk kegiatan yang memanfaatkan potensi sumber daya alam dan lingkungan. Sedangkan obyek wisata alam adalah sumberdaya alam yang berpotensi dan berdaya tarik bagi wisatawan serta ditujukan untuk pembinaan cinta alam baik dalam kegiatan alam maupun setelah pembudidayaan. Jadi dapat disimpulkan bahwa wisata alam merupakan pemanfaatan sumber daya alam yang ditata dengan baik sehingga dapat menimbulkan rasa senang, rasa indah, nyaman dan bersih dengan menggunakan konservasi sumber daya alam serta lingkungan sebagai daya tariknya. wisata alam adalah suatu kegiatan perjalanan yang dilaksanakan pada tempat-tempat yang berhubungan dengan alam, seperti gunung, hutan, gua, lembah, sungai, pesisir, laut, air terjun, danau, lembah sempit dan lain sebagainya. Salah satu bentuk kegiatan wisata alam yang berkembang saat ini adalah ekowisata. Ekowisata lebih populer dan banyak dipergunakan dibandingkan dengan terjemahan yang seharusnya yaitu ecotourism yaitu ekoturisme.

Ekowisata mengalami pengertian dari waktu ke waktu. Namun pada hakikatnya ekowisata dapat diartikan sebagai bentuk wisata yang bertanggung jawab terhadap kelestarian area yang masih alami, memberi manfaat secara ekonomi dan mempertahankan keutuhan budaya bagi masyarakat. Ekowisata merupakan suatu bentuk wisata yang sangat erat dengan prinsip konservasi. Bahkan dalam pengembangan ekowisata juga menggunakan strategi konservasi. Dengan demikian ekowisata sangat tepat dan berdaya guna dalam mempertahankan keutuhan dan keaslian ekosistem di areal yang masih alami. Bahkan dengan ekowisata, kelestarian alam dapat ditingkatkan kualitasnya.
Ekowisata dapat dipahami sebagai perjalanan yang disengaja ke kawasan-kawasan alamiah untuk memahami budaya dan sejarah lingkungan tersebut sambil menjaga agar keutuhan kawasan tidak berubah dan menghasilkan peluang untuk pendapatan masyarakat sekitarnya sehingga mereka merasakan manfaat dari upaya pelestarian sumber daya alam.

Ekowisata merupakan perjalanan wisata ke suatu tempat lingkungan baik alam yang alami maupun yang buatan serta budaya yang ada bersifat inormaif dan partisipatif yang bertujuan untuk menjamin kelestarian alam dan sosial budaya. Ekowisata menitik beratkan pada tiga hal utama yaitu keberlangsungan alam atau ekologi, memberikan manfaat ekonomi, dan secara psikologi dapat diterima dalam kehidupan sosial masyarakat. Jadi kegiatan ekowisata secara langsung memberi akses kepada semua orang untuk melihat, mengetahui dan menikmati pengalaman alam, intelektual dan budaya masyarakat lokal.

\subsection{Rusa Sambar}

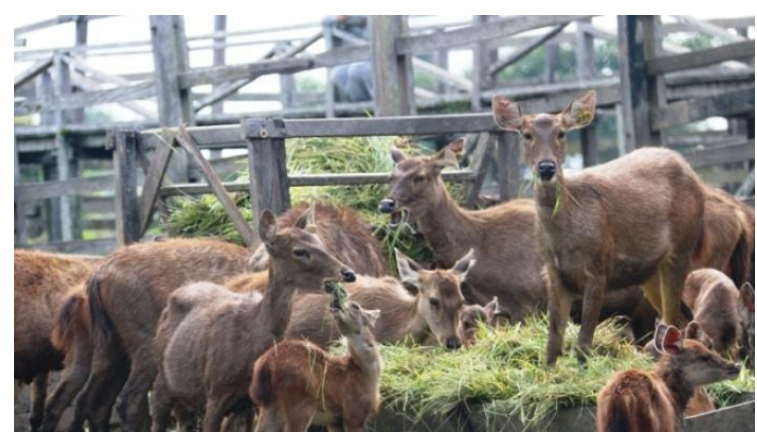

Gambar 2. Rusa sambar

Rusa merupakan salah satu jenis satwa yang termasuk dalam Bangsa (Ordo) Artiodactyla, Anak Bangsa (Subordo) Ruminansia dan Suku (Family) Cervidae. Suku Cervidae terbagi atas 6 Anak Suku (Subfamily), yaitu Rangiferinae, Alcinae, Hidropotinae, Muntiacinae, Odocilinae, dan Cervinae. Umumnya, pembahasan tentang rusa biasanya semua jenis satwa yang termasuk dalam Suku Cervidae. Saat ini diketahui tidak kurang dari 16 marga (genus), 38 jenis (spesies), dan 189 anak jenis (subspesies) rusa yang tersebar ke seluruh dunia, mulai dari daerah beriklim dingin di daratan Eropa hingga ke daerah subtropis dan tropis di daratan Asia. Hanya Benua Afrika yang sesuai dengan sebaran aslinya tidak memiliki keluarga rusa. Ukuran tubuh rusa dewasa bervariasi dari yang terbesar 
sebesar sapi muda, hingga yang terkecil sekecil anak kambing.

Rusa Sambar (Cervus Unicolor), Rusa Timor (Cervus timorensis), Rusa Bawean (Axis kuhlii), dan Mucak/Kijang (Muntiacus muntjak) merupakan jenis rusa yang di temui di Indonesia. Jenis rusa tersebut tersebar luas di pulau besar dan kecil di Indonesia. Selain dari empat jenis rusa di atas, di Indonesia juga dijumpai rusa tropis yang bukan asli Indonesia, yaitu Rusa Chital/Totol (Axis axis) yang berasal dari India. Di Kalimantan, Rusa Sambar dikenal dengan nama Rusa Payau. Rusa merupakan hewan herbivora sehingga makanan pokoknya berupa hijauan. Pakan untuk rusa selain dari rerumputan atau hijauan lainnya, sebagai tambahannya dapat berupa konsentrat, sayur mayur, umbi-umbian, atau limbah pertanian. Pada habitat alami, hewan ini biasanya mencari makanan pada pagi dan sore hari menjelang petang tetapi bersembunyi pada siang hari.

\subsection{Virtual Reality}

Virtual Reality (VR) atau realitas maya adalah teknologi yang membuat pengguna dapat berinteraksi dengan suatu lingkungan yang disimulasikan oleh komputer (computersimulated environment)[6], suatu lingkungan sebenarnya yang ditiru atau benar-benar suatu lingkungan yang hanya ada dalam imaginasi. Konsep VR mengacu pada sistem prinsip-prinsip, metode dan teknik yang digunakan untuk merancang dan menciptakan produk-produk perangkat lunak untuk digunakan oleh bantuan dari beberapa sistem komputer multimedia dengan sistem perangkat khusus [7].

Banyak pendidik menjelajahi model belajar untuk menerima bahwa teknologi komputer dapat memberikan alternatif untuk pengaturan kehidupan nyata [8]. Lingkungan tersebut harus Menyediakan konteks otentik yang mencerminkan pengetahuan yang akan digunakan dikehidupan nyata, Menyediakan kegiatan yang sebernarnya. Menyediakan peran ganda dan perspektif. Mendukung pengetahuan yang kolaboratif [4]. Memberikan pembinaan pada saat-saat kritis. Lingkungan realitas maya terkini umumnya menyajikan pengalaman visual, yang ditampilkan pada sebuah layar komputer atau melalui sebuah penampil stereokopik, tapi beberapa simulasi mengikut sertakan tambahan informasi hasil pengindraan, seperti suara melalui speaker atau headphone [9]. Beberapa sistem haptic canggih sekarang meliputi informasi sentuh, biasanya dikenal sebagai umpan balik kekuatan pada aplikasi berjudi dan medis.

Para pemakai dapat saling berhubungan dengan suatu lingkungan sebetulnya atau sebuah artifak maya baik melalui penggunaan alat masukan baku seperti keyboard dan mouse, atau melalui alat multimodal seperti sarung tangan terkabel, Polhemus boom arm, dan ban jalan segala arah. Lingkungan yang ditirukan dapat menjadi mirip dengan dunia nyata, sebagai contoh, simulasi untuk pilot atau pelatihan pertempuran, atau dapat sangat berbeda dengan kenyataan, seperti di VR game [10]. Dalam praktik, sekarang ini sangat sukaruntuk menciptakan pengalaman Realitas maya dengan kejernihan tinggi, karena keterbatasan teknis atas daya proses, resolusi citra dan lebar pita komunikasi. Bagaimanapun, pembatasan itu diharapkan untuk secepatnya diatasai dengan berkembangnya pengolah, pencitraan dan teknologi komunikasi data yang menjadi lebih hemat biaya dan lebih kuat dari waktu ke waktu (Sihite, 2013).

\section{Metode Penelitian}

Metode yang digunakan pada penelitian ini menggunaka metode pengembangan Multimedia Development Life Cycle (MDLC) agar pengembangan dari aplikasi tersebut dapat memenuhi standar kualitas [6].

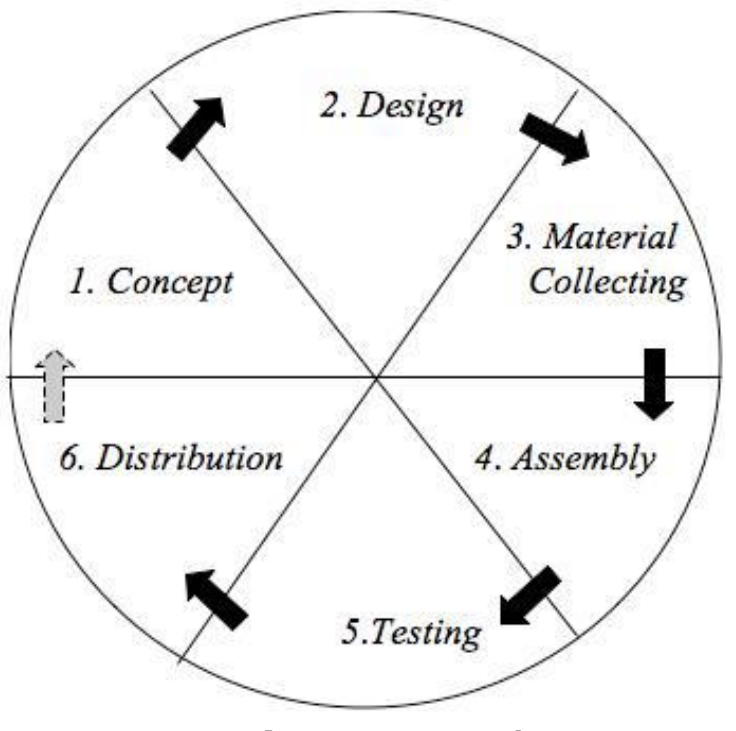

Gambar 3. MDLC Cycle

\subsection{Multimedia Development Life Cycle (MDLC)}

Metode pengembangan Multimedia Development Life Cycle (MDLC) dilakukan berdasarkan enam tahapan, yaitu concept (pengonsepan), design (pendesignan), material collecting (pengumpulan materi), assembly 
(pembuatan), testing (pengujian), dan disribution (pendistribusian).

\subsection{Concept}

Dalam fase ini, peneliti menentukan tujuan video promosi yaitu untuk bisa menarik pengunjung wisata penangkaran rusa dan menambah pengetahuan masyarakat dan wisatawan luar daerah mengenai ekowisata penangkaran rusa di Penajam Paser Utara. Serta memudahkan masyarakat dan wisatawan luar daerah untuk mendapat informasi rusa sambar yang ada di Penajam Paser Utara.

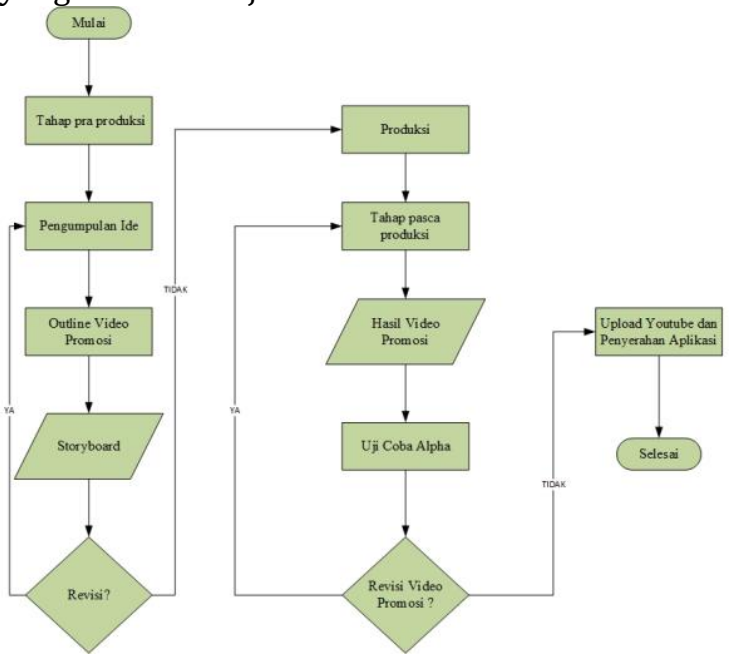

Gambar 4. Flowchart Konsep

\subsection{Design}

Tahap desain melakukan pembuatan desain tampilan visual, interface, storyboard,dan struktur navigasi. Pada desain multimedia diperlukan pemetaan struktur navigasi yang menggambarkan hubungan antara beberapa konten dan membantu mengorganisasi konten dengan desain. Selain itu pada tahap ini juga dibuat perancangan algoritma untuk aplikasi evaluasai pembelajaran. Tahap ini biasanya menggunakan storyboard untuk menggambarkan deskripsi tiap scene, dengan mencantumkan semua objek multimedia dan tautan scene lain dan bagan alir untuk menggambarkan aliran dari satu scene ke scene yang lain [11].
Tabel 1. Skenario

\begin{tabular}{|l|l|}
\hline No & \begin{tabular}{l} 
Keterangan \\
\hline 1
\end{tabular} \\
\hline 2 & $\begin{array}{l}\text { Menampilkan } \\
\text { logo unmul } \\
\text { dan logo } \\
\text { kukar serta } \\
\text { diikuti judul } \\
\text { dari video } \\
\text { Virtual tour }\end{array}$ \\
\hline
\end{tabular}




\subsection{Material Collecting}

Pada langkah ini, data terkait video promosi penangkaran rusa diambil dari wawancara kepada pegawai UPTD. Pembibitan Ternak dan Hijauan Pakan Ternak pengelola penangkaran rusa, membaca buku, dan mencari sumbersumber lainnya dari internet. Sedangkan untuk materi terkait Virtual Reality, penulis mendapatkan materi dari buku referensi, jurnal penelitian, dan internet.

\subsection{Assembly}

Tahap assembly atau pembuatan adalah tahap dimana semua objek atau bahan multimedia yang telah dikumpulkan dibuat [8]. Pembuatan aplikasi berdasarkan pada flowchart dan pembuatan video berdasarkan storyboard yang telah dibuat sebelumnya. Semua objek atau material dibuat dan digabungkan menggunakan aplikasi Unity 3D menjadi satu aplikasi yang utuh. Dalam lsngksh ini digunakan dua software seperti, Premiere Pro, dan Unity 3D.

\subsection{Testing}

Tahap ini disebut juga sebagai tahap pengujian alpha atau pengujian secara sepihak dan tidak bersama user dimana pengujian dilakukan oleh pembuat atau lingkungan pembuatnya sendiri. Dalam pengujian video ini dilakukan pengecekan ketepatan gyroscope berdasarkan gerak segala arah [12]. Pengujian selanjutnya adalah pengujian terhadap kualitas gambar yang dihasilkan, apakah sudah layak untuk dilihat dan hasilnya sesuai dengan resolusi layar yang dipakai yaitu 16:9. Pengujian selanjutnya dengan menggunakan pengujian kuisioner yang mengacu pada tujuan penelitian yaitu membuat masyarakat tertarik untuk dating ke penangkaran rusa.

\subsection{Distribution}

Dalam langkah ini, aplikasi yang telah selesai di uji dan dinyatakan baik sesuai dengan tujuan pembuatan, akan didistribusikan dengan cara mengunggah ke akun Youtube dan membagikan aplikasi melalui Share-It karena peneulis tidak sanggup mendistribusikan aplikasi melalui google PlayStore.

\section{Hasil Dan Pembahasan}

\subsection{Proses Penyutingan Video}

Pada tahap ini dilakukan penyuntingan dengan menggunakan Adobe Premiere Pro CC 2017 terhadap video 360 drajat yang diambil sebelumnya dilokasi penangkaran rusa, dengan terlebih dahulu membuat Project Baru pada Premiere Pro.

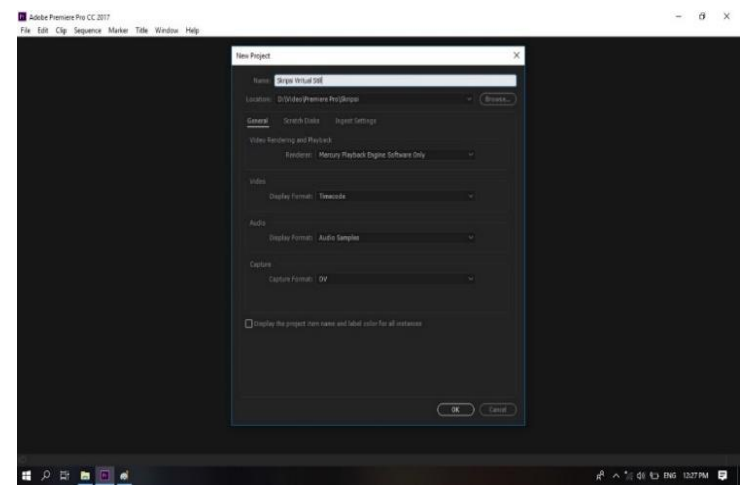

Gambar 5. Pembuatan Project Baru

Tabel 2. Pengelompokkan Data VIDEO

\begin{tabular}{|c|c|}
\hline Footage Mentah & Video Promosi \\
\hline 20190513_0901.mp4 & - \\
\hline 20190513_0902.mp4 & Virtual Experience \\
\hline 20190513_0903.mp4 & \\
\hline 20190513_0904.mp4 & Virtual Still \\
\hline
\end{tabular}

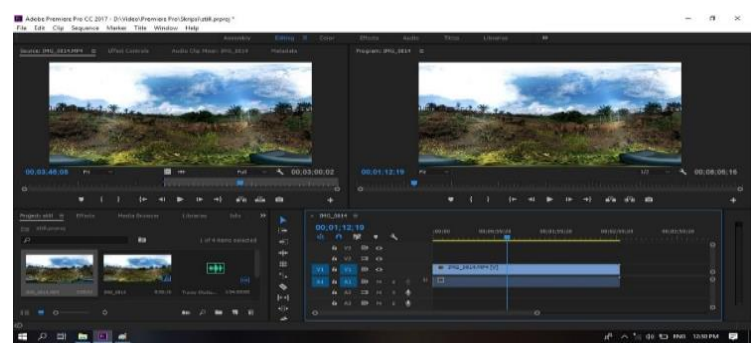

Gambar 6. Tampilan Editing

Editing video merupakan suatu proses kegiatan menjadikan video lebih tertata rapi dan bisa dinikmati oleh user. Bagian yang meliputi editing video ada banyak yaitu pemotongan gambar, pengaturan ukuran, pengaturan suara video, menambahkan judul, transisi, dan efek lainnya.

Pemotongan gambar dilakukan dengan cara menggunakan razol toll yang fungsinya untuk membuang gambar yang tidak dibutuhkan. Pengaturan ukuran digunakan untuk mengatur 
ukuran gambar besar atau kecil ukuran yang diperlukan. Penambahan judul bisa digunakan untuk membuat credit atau judul dari video tersebut. Transisi dipegunakan untuk membuat potongan pada video menjadi lebih bagus dan nyaman dilihat oleh penonton.

\subsection{Pembuatan Opening Aplikasi}

Untuk mencapai tujuan penelitian ini yaitu sebuah media promosi agar mewujudkan penangkaran rusa menjadi tempat ekowisata di penajam paser utara maka penulis menambahkan video motion graphic pada awalan saat membuka aplikasi. Pada pembuatan video ini dilakukan desain gambar terlebih dahulu dengan menggunakan aplikasi corel draw. Setelah mendesain gambar selanjutnya bisa langsung dimasukkan ke dalam aplikasi edit video yaitu adobe premiere pro. Berikut adalah proses pembuatan opening motion grafik bisa dilihat di gambar 7.

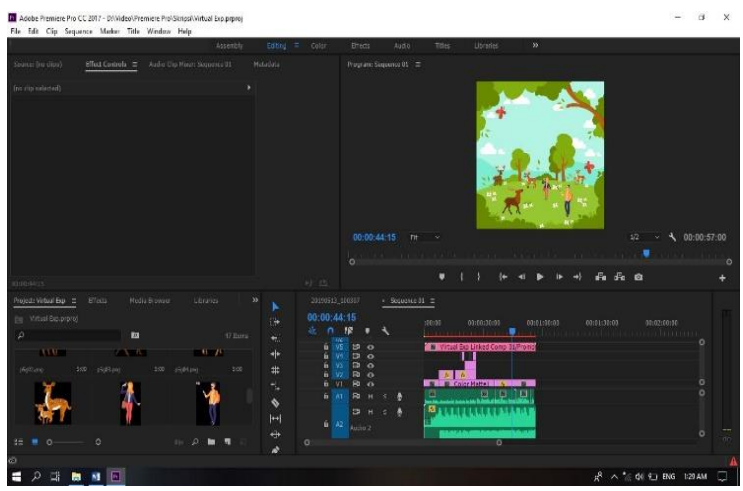

Gambar 7. Tampilan Editing

\subsection{Pembuatan Aplikasi VR}

Untuk membuat aplikasi Virtual Reality menggunakan aplikasi Unity hal pertama yang harus dilakukan adalah membuat project baru serta menentukan lokasi penyimpanannya setelah itu klik Create project untuk melanjutkan. import seluruh asset yang di gunakan untuk membuat aplikasi Virtual Reality contohnya seperti seluruh video, asset Insideout dan foto yang berguna untuk membuat VR[13].

Penambahan asset dilakukan untuk mendukung proses pembuatan aplikasi yang berupa penambahan package, panel, sphere, button, dll. Penambahan package merpakan salah satu hal yang penting dalam membuat aplikasi ini.
Penambahan package dapat dilakukan dengan cara klik asset pada menu bar lalu import package dan custom package.

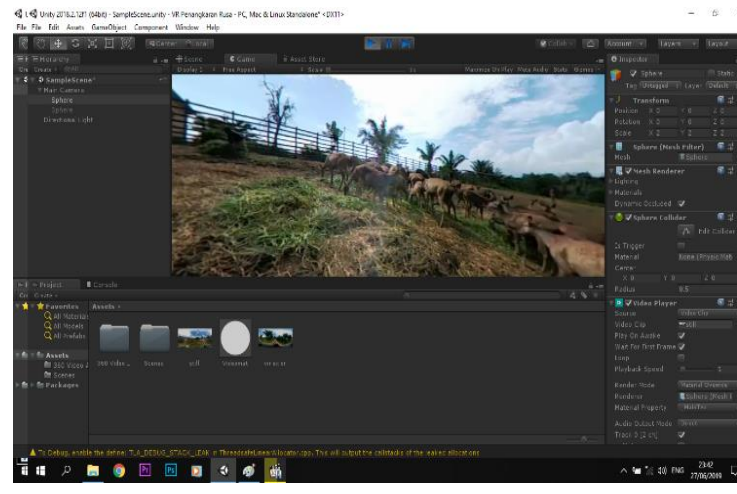

Gambar 8. Tampilan Pembuatan Aplikasi

\subsection{Uji Aplikasi}

Pada Aplikasi yang telah berhasil dikembangkan ini kemudian diuji pada beberapa smartphone untuk mengetahui apakah aplikasi dapat di install dan berjalan dengan lancar dan gyroscope dapat berjalan pada versi android. Pengujian perangkat dilakukan secara konvensiona dengan menginstal disetiap prangkat yang ada. Berikut ini merupakan hasil ujicoba yang dilakukan terhadap beberapa smartphone:

TABEl I. PEngujian APlikasi Pada SMARTPhone

\begin{tabular}{|c|c|c|c|c|}
\hline $\begin{array}{c}\text { Nama } \\
\text { Perangkat }\end{array}$ & $\begin{array}{c}\text { Versi } \\
\text { Android }\end{array}$ & Resolusi Layar & Gyroscope & Kelancaran \\
\hline Redmi 3 & 5.1 & $1920 \times 1080(16: 9)$ & Bisa & Lancar \\
\hline Redmi 5 Plus & 7.0 & $2160 \times 1080(18: 9)$ & Bisa & Lancar \\
\hline
\end{tabular}

Dari ujicoba sejumlah prangkat aplikasi ini berjalan dengan baik dan tidak ada kendala sedikitpun. Mulai dari resolusi layar dengan resolusi 16:9 atau 18:9 aplikasi ini mampu untuk dijalankan dengan indikasi gyroscope berjalan dengan lancer dan aplikasi juga tidak force close. Namun aplikasi ini tidak bisa dijalankan dengan versi android dibawahmulai dari versi android KitKat (4.4) karena APi yang digunakan tidak mendukung. Salah satu uji coba yang dilakukan di prangkat Redmi Note 5 


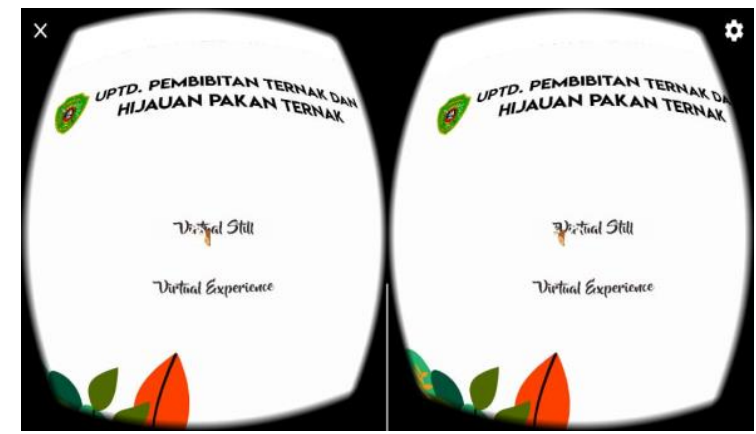

Gambar 9. Tampilan Virtual Reality Di Perangkat Android

\subsection{Distribusi}

Distribusi dilakukan setelah semua proses dalam pembuatan video atau dalam membangun aplikasi telah selesai, distribusi dilakukan agar video yang sudah di bentuk sedemikian rupa dapat dinikmati oleh seluruh masyarakat dan di harapkan dapat menambah pengetahuan serta semaklin tertarik untuk mengunjungi Penangkaran Rusa. Adapun untuk melakukan pendistribusian video dilakukan secara online dengan menggunakan social media YouTube. Sedangkan pada aplikasi dapat dilakukan beberapa cara baik online maupun offline, salah satu cara dalam pendistribusian offline adalah dengan menggunakan Share-it. Berikut contoh penggunaan Share-it smartphone hasil uji coba yang dilakukan terhadap beberapa smartphone.

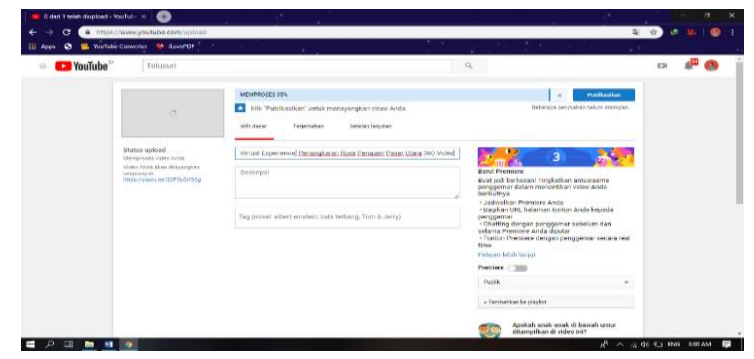

Gambar 10. Distribusi Online

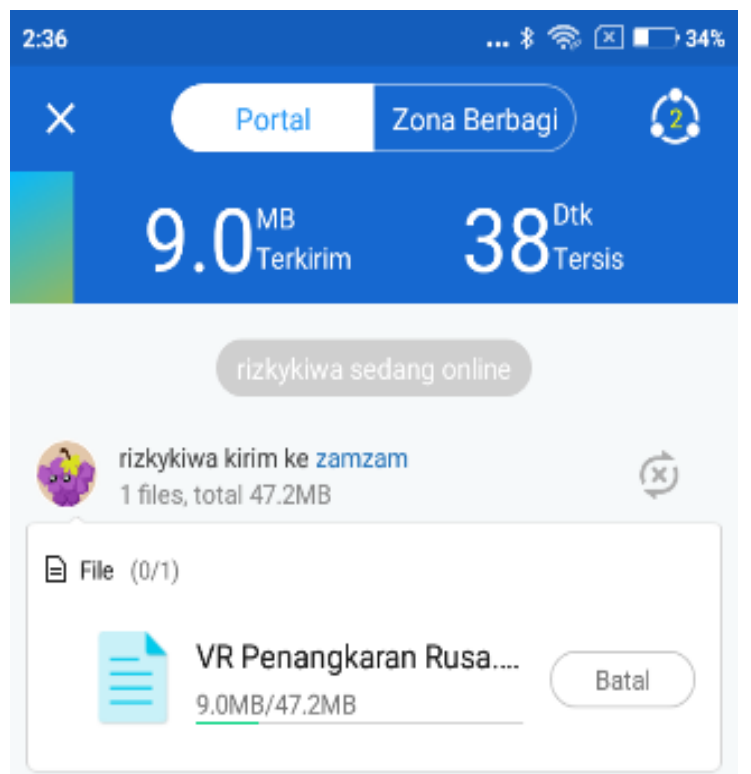

Gambar 11. Distribusi Offline

\subsection{Pembahasan}

Aplikasi Virtual Reality penangkaran rusa berhasil diimplementasi dan dijalankan dengan lancar pada perangkat android dengan versi android 5.0 (Lolipop) hingga versi android terbaru 9.0 (Pie). Namun pada pengujian aplikasi yang dilakukan, terdapat masalah yaitu tidak bisa memakai tombol didalam video dikarenakan video ditempatkan didalam sphere yang menutupi semua video dan posisi main camera yang juga berada didalam sphere sehinggapeneliti mengalami masalah untuk membuat menu tombol didalam video. Namiun peneliti memiliki ide untuk mengaktifkan tombol kembali di android agar stelah memainkan video bisa kembali ke menu utama untuk memilih video yang lainnya.

Walaupun memiliki masalah tersebut, secara fungsi aplikasi ini sudah bisa dijalankan dengan baik. Fitur-fitur yang diberikan juga lancer dan tidak terdapat masalah. Seperti gyroscope yang berjalan lancer serta pointer yang bisa dipakai untuk memilih. 


\section{Kesimpulan dan Saran}

Berdasarkan Berdasarkan hasil dan pembahasan yang telah dijabarkan pada bab sebelumya, maka dapat disimpulkan, Aplikasi Virtual Reality (VR) Media Promosi Penangkaran Rusa Sambar telah berhasil dirancang dan dibangun dengan memanfaatkan tools pengembangan Premiere Pro, dan Unity3D. Aplikasi VR Media Promosi Penangkaran Rusa Sambar yang dibangun mampu memvisualisasikan objek-objek kawasan yang berada di penangkaran rusa Penajam Paser Utara. Berdasarkan pengujian perangkat, aplikasi dapat berjalan dengan lancar pada perangkat android dengan versi android 5.0 (Lolipop) hingga versi android terbaru 9.0 (Pie). Media Promosi Penangkaran Rusia juga bisa digunakan di social media YouTube dan dapat diakses dengan tampilan video 360 derajat maupun tampilan CardBoard untuk kacamata VR.

Berdasarkan hasil evaluasi pada aplikasi VR media promosi penangkaran rusa, terdapat beberapa saran untuk pengembangan aplikasi selanjutnya adalah diharapkan kualitas video 360 lebih ditingkatkan lagi dan menggunakan metode ini diharapkan bisa menggunakan lebih banyak motion text sehingga menyampaikan informasi lebih jelas. Pada pengembangan aplikasi selanjutnya, diharapkan dapat memperbanyak fitur seperti tombol bantuan, dan memperbagus tampilan aplikasi serta distribusi aplikasi diharapkan bisa menggunakan Android PlayStore.

\section{Daftar Pustaka:}

[1] D. Satria, "Strategi Pengembangan Ekowisata Berbasis Ekonomi Lokal Dalam Rangka Program Pengentasan Kemiskinan Di Wilayah Kabupaten Malang," J. Indones. Appl. Econ., vol. 3, no. 1, pp. 1-2009, 2009.

[2] L. Zhou and Q. Lin, “Virtual tour's imapct on destination image," 2012 Int. Symp. Manag. Technol. ISMOT 2012, pp. 641643, 2012.

[3] W. Chen, "Historical Oslo on a handheld device -a mobile augmented reality application," Procedia Comput. Sci., vol. 35, no. C, pp. 979-985, 2014.

[4] M. B. Firdaus, J. A. Widians, and J. Y. Padant, "Augmented reality for interactive promotion media at Faculty of Computer Science and Information Technology
Mulawarman University," J. Phys. Conf. Ser., vol. 1341, no. 4, 2019.

[5] S. Gebhardt et al., "FlapAssist: How the integration of VR and visualization tools fosters the factory planning process," 2015 IEEE Virtual Real. Conf. VR 2015 Proc., pp. 181-182, 2015.

[6] M. B. Firdaus, E. Budiman, joan angelina Widians, novel maringan Sinaga, S. Fadli, and F. Alameka, "Augmented Reality for Office and Basic Programming Laboratory Peripheral," 2018 2nd East Indones. Conf. Comput. Inf. Technol., pp. 41-45, 2018.

[7] V. Siang et al., "Interactive Holographic Application using Augmented Reality EduCard and 3D Holographic Pyramid for Interactive and Immersive Learning," 2017 IEEE Conf. e-Learning, eManagement e-Services, pp. 73-78, 2017.

[8] B. Cahyono, M. B. Firdaus, E. Budiman, and M. Wati, "Augmented Reality Applied to Geometry Education," 2018 2nd East Indones. Conf. Comput. Inf. Technol., pp. 299-303, 2018.

[9] J. Xiao, M. M. Hannuksela, T. Tillo, M. Gabbouj, C. Zhu, and Y. Zhao, "Scalable bit allocation between texture and depth views for 3-D video streaming over heterogeneous networks," IEEE Trans. Circuits Syst. Video Technol., vol. 25, no. 1, pp. 139-152, 2015.

[10] O. Shaikh, Y. Sunt, and A. Stevenson Won, "Movement Visualizer for Networked Virtual Reality Platforms," 25th IEEE Conf. Virtual Real. 3D User Interfaces, VR 2018 Proc., pp. 681-682, 2018.

[11] M. Durkin, P. McGowan, and L. Murray, "Perspectives on the potential for social media to improve communication in small business-bank relationships," Int. J. Entrep. Innov., vol. 15, no. 4, pp. 251-264, 2014.

[12] Imtihan, K., \& Basri, M. H. (2019). SISTEM INFORMASI PEMBUATAN MANIFEST MUATAN KAPAL BERBASIS DEKSTOP DAN ANDROID. Jurnal Manajemen Informatika dan Sistem Informasi, 2(2), 69-76.

[13] Khairul Imtihan. "Perencanaan Strategi Sistem Informasi Pendidikan Pada Sekolah Tinggi Manajemen Informatika dan Komputer (STMIK) Lombok." Bianglala Informatika 3, no. 2 (2015).

[14] E. Budiman, U. Haryaka, J. R. Watulingas, and F. Alameka, "Performance rate for implementation of mobile learning in 
network," 2017 4th Int. Conf. Electr. Eng. Comput. Sci. Informatics, no. September, pp. 1-6, 2017.

[15] Sofiansyah Fadli and Khairul Imtihan, "Implementation of MOORA Method in Evaluating Work Performance of Honorary Teachers," Sinkron: JUrnal dan
Penelitian Teknik Informatika, vol. 4, no. 1, pp. 128-135, 2019.

[16] C. Hutton and E. Suma, "A realistic walking model for enhancing redirection in virtual reality," Proc. - IEEE Virtual Real., vol. 2016-July, pp. 183-184, 2016. 